\title{
Posterior cornea and thickness changes after scleral lens wear in keratoconus patients
}

\author{
Maria Serramito $^{\mathrm{a}}$, Carlos Carpena-Torres ${ }^{\mathrm{a}}$, Jesús Carballo ${ }^{\mathrm{a}}$, David Piñero ${ }^{\mathrm{b}, \mathrm{c}}$, Michael Lipson ${ }^{\mathrm{d}}$, \\ Gonzalo Carracedo ${ }^{\mathrm{a}, \mathrm{e}, *}$ \\ a Department of Optics II (Optometry and Vision), Faculty of Optics and Optometry, Universidad Complutense de Madrid, Madrid, Spain \\ ${ }^{\mathrm{b}}$ Group of Optics and Visual Perception, Department of Optics, Pharmacology and Anatomy, University of Alicante, Spain \\ ${ }^{\mathrm{c}}$ Department of Ophthalmology (OFTALMAR), Vithas Medimar International Hospital, Alicante, Spain \\ d Department of Ophthalmology and Visual Science, University of Michigan, Northville, MI, USA \\ e Ocupharm Group Research, Department of Biochemistry and Molecular Biology IV, Faculty of Optics and Optometry, Universidad Complutense de Madrid, Madrid, Spain
}

\section{A R T I C L E I N F O}

\section{Keywords:}

Scleral lenses

Keratoconus

Corneal curvature

Corneal aberrations

Anterior chamber

Corneal thickness

\begin{abstract}
A B S T R A C T
Purpose: To evaluate the changes in the corneal thickness, anterior chamber depth and posterior corneal curvature and aberrations after scleral lens wear in keratoconus patients with and without intrastromal corneal ring segments (ICRS).

Methods: Twenty-six keratoconus subjects (36.95 \pm 8.95 years) were evaluated after $8 \mathrm{~h}$ of scleral lens wear The subjects were divided into two groups: those with ICRS (ICRS group) and without ICRS (KC group). The study variables evaluated before and immediately after scleral lens wear included corneal thickness evaluated in different quadrants, posterior corneal curvature at 2, 4, 6 and $8 \mathrm{~mm}$ of corneal diameter, posterior corneal aberrations for 4, 6 and $8 \mathrm{~mm}$ of pupil size and anterior chamber depth.

Results: There was a statistically significant corneal thinning $(\mathrm{p}<0.05)$ in the inferior region of the KC group and in the superior region of the ICRS group. No change ( $p>0.05)$ in the anterior chamber depth was found. The KC group showed a steepening $(\mathrm{p}<0.05)$ in the temporal quadrant and a flattening that mainly affected to the superior-nasal quadrant. The ICRS group showed a steepening $(\mathrm{p}<0.05)$ that mainly affected to the superior-nasal quadrant. Regarding posterior corneal aberrations, only changes ( $<<0.05$ ) in Z4 for $8 \mathrm{~mm}$ and Z8 for $4 \mathrm{~mm}$ were found in the KC group.

Conclusions: Short-term scleral lens wear showed a thinning of the cornea and changes in the posterior corneal curvature affects different regions in keratoconus patients with and without ICRS.
\end{abstract}

\section{Introduction}

Scleral contact lenses (ScCL) are rigid gas permeable with a large diameter. They have gained renewed interest during the last decade and have become an important tool in visual rehabilitation of patients with an irregular corneal surface from conditions such as keratoconus, keratoglobus, penetrating keratoplasty [1] and severe ocular surface disorders such as Sjogren's syndrome [2], exposure keratopathy and Steven- Johnson's Syndrome [3].

With ScCL, the post-lens tear film neutralizes the majority of corneal astigmatism, to correct most of the higher order aberrations and provides the cornea with continuous hydration [4]. Furthermore, patients tolerate scleral lenses better than corneal RGP lenses due to better comfort, excellent visual acuity and ideal centration [5].

ScCL are manufactured with high oxygen permeable materials, to maximize passage of oxygen through the lens [6]. The potential effect of ScCL on corneal hypoxia and oedema has been studied $[7,8]$. But there is not a consensus on the effect of scleral lens wear on corneal thickness, related to oedema. Corneal swelling has been shown by some authors, while other authors have found corneal thinning [9-13]. Studies of keratoconus patients have shown significant increase in central corneal thickness after eight hours [10] and after one week wearing scleral contact lenses [9]. However, there are not published studies that analyze the effect of ScCL wear on the corneal thickness in different quadrants.

Several studies have shown the effects ScCL have on the ocular surface in healthy patients compared to keratoconus patients, evaluating anterior corneal curvature, tear physiology and corneal temperature $[9,10,12,14-16]$, but only one study has been performed on the effect of scleral lens wear on the posterior corneal curvature in

\footnotetext{
* Corresponding author at: Faculty of Optics, Department Optics II (optometry and Vision), C/Arcos del Jalon 118, 28037, Madrid, Spain.

E-mail address: jgcarrac@ucm.es (G. Carracedo).
} 
healthy patients [11]. Their results cannot be assumed to be similar for keratoconus patients and patients with intrastromal corneal rings (ICRS), because of their differences in corneal biomechanics, anterior and posterior corneal physiology [17].

Changes in corneal thickness and posterior corneal curvature during ScCL wear can compromise visual function [18]. The aim of this study was to investigate the changes in corneal thickness, and posterior corneal curvature and aberrometric parameters across the corneal posterior surface before and immediately after eight hours of wearing a ScCL in keratoconus subjects with and without ICRS.

\section{Material and methods}

Twenty-six keratoconus subjects were recruited for the study in the Optometry Clinic of the Faculty of Optics and Optometry of the University Complutense of Madrid to participate in an experimental, short-term study. The inclusion criteria was to have keratoconus at least grade I (following the Amsler-Krumeich classification) with or without intracorneal rings segments implanted. The exclusion criteria were presence of ocular allergies and their treatment reported by the patients, atopy and ocular and lid disease. Subjects were divided into two groups: keratoconus without ICRS (KC group) and with intracorneal ring segments (ICRS) (ICRS group). The subjects in this study were the same subjects from other studies conducted by the research group on ocular temperature [15], tear turbidity [19] and ocular physiology [14] changes after ScCL wear. Moreover, the study was conducted in compliance with good clinical practice guidelines, institutional review board regulations and the tenets of the Declaration of Helsinki [20]. Subjects signed an informed consent and were free to drop out the research at any time. In addition, the study was approved by the Ethics Committee (CEIC) of the Hospital Clínico San Carlos of Madrid.

One week prior to the experimental day, all subjects were fit with ICD 16.5 (Paragon Vision Sciences, Mesa, AZ USA) ScCL with an overall diameter of $16.5 \mathrm{~mm}$. All lenses were fit by the same practitioner. The ScCL was selected to provide a corneal clearance of $300-400 \mu \mathrm{m}$, following the manufacturer's fitting guide. The corneal clearance was evaluated by slit lamp examination using an optic section to estimate the tear layer thickness compared to the lens thickness. Once the lenses were calculated, the adequate lens for each patient was ordered to the manufacturer.

All subjects were instructed to wear the ScCL for eight hours. Subjects who were contact lens wearers prior to the study were required to stop wearing contact lens at least 1 week before the evaluation day. Topographic and aberrometric parameters were evaluated before lens wear and immediately after lens removal after eight hours of wear with the Oculus Pentacam system (Oculus, Wetzlar, Germany). The Oculus Pentacam system is a rotating Scheimpflug camera. The rotational measuring procedure generates three-dimensional Scheimpflug images of the anterior segment of the eye from as many as 25,000 true elevation points. The analysis of the anterior eye segment includes a calculation of different types of maps. Three measurements that had an examination quality specification graded as "OK" were done. Posterior corneal curvature, corneal thickness, anterior chamber depth and Zernike coefficients of the posterior cornea were assessed. Posterior corneal curvature was evaluated at 2, 4, 6 and $8 \mathrm{~mm}$ of corneal diameter and at $0^{\circ}, 45^{\circ}, 90^{\circ}, 135^{\circ}, 180^{\circ}, 225^{\circ}, 270^{\circ}$ and $315^{\circ}$ meridians. Corneal thickness was measured central, nasal, temporal, superior and inferior quadrants. Finally, posterior corneal aberrations were analyzed considering pupils of 4, 6 and $8 \mathrm{~mm}$. Before and after ScCL wear measurements were performed in the same day, at least one week after to be ordered and only in one eye of each patient, selected randomly. More details about the scleral lens in Table 1.

\subsection{Statistical analysis}

Data were analyzed using the statistical software SPSS 22.0 (SPSS,
Table 1

Technical details of the contact lenses being used and parameters fitted to patients in this study.

\begin{tabular}{ll}
\hline Brand & ICD 16.5 \\
\hline Design's owner & Paragon Vision Science \\
Manufacturer & Lenticon SA \\
Material (USAN) & Paflufocon D \\
Dk (barrer) & 100 \\
Water Content (\%) & $<1 \%$ \\
tc (mm) & $0.30(-3.00)$ \\
Power (D) & $+1.00 \mathrm{D}$ to $-16.00 \mathrm{D}$ \\
Overall Diameter (mm) & 16.50 \\
Sagittal height (microns) & $3900-5600$ \\
\hline
\end{tabular}

Inc., Chicago, IL). Sample size calculations were performed with statistical software (Granmo 6.0; Institut Municipal d'Investigacion Medica, Barcelona, Spain). Posterior corneal curvature was the main variable, based on a two-sided statistical significant threshold of 0.05 and a risk of 0.20 , for a standard deviation of 0.6 units, in order to detect a difference of 0.7 units, at least 12 subjects were needed to be included in each group to establish statistical significance. The values presented are the means \pm SD of the experiments performed. Normal distribution of variables was assessed by the Shapiro-Wilk normality test. Differences between topographic parameters prior to lens wear and after lens removal after eight hours were estimated by Student-t test for paired samples. Differences between aberrometric parameters were evaluated using the Wilcoxon test. $\mathrm{P}<0.05$ was considered statistically significant.

\section{Results}

The range age of the patients was from 25 to 51 years old (mean: $36.95 \pm 8.95$ years. Eleven patients, five in the KC group and six in the ICRS group, wore ScCL before the beginning of the study. There were no statistical differences between these patients who wore ScCL and the new wearers for any parameter evaluated. Corneal pachymetry in different quadrants of the cornea and the anterior chamber height changes after scleral lens wear are summarized in Table 2. There was a statistically significant decrease $(\mathrm{p}<0.05)$ in superior pachymetry for all subjects and the ICRS group. In the KC group, there was a statistically significant decrease $(\mathrm{p}<0.05)$ in inferior pachymetry. No change $(p>0.05)$ in anterior chamber depth was found in any group.

Table 3 shows the posterior corneal curvature values before and after ScCL wear for all subjects. There was a statistically significant steepening ( $\mathrm{p}<0.05)$ at $8 \mathrm{~mm}$ in $0^{\circ}$ meridian, at $4 \mathrm{~mm}$ in $45^{\circ}$ and $90^{\circ}$ meridians, at 4 and $6 \mathrm{~mm}$ in $135^{\circ}$ meridian and at $6 \mathrm{~mm}$ in $225^{\circ}$ meridian. In contrast, there was a statistically significant flattening ( $\mathrm{p}<0.05$ ) at $8 \mathrm{~mm}$ in $225^{\circ}$ and $270^{\circ}$ meridians and at 4 and $6 \mathrm{~mm}$ in $315^{\circ}$ meridian.

In the KC group, Table 4 shows the posterior corneal curvature values before and after ScCL wear. Additionally, these changes are graphically represented in Fig. 1 . There was a statistically significant steepening ( $\mathrm{p}<0.05$ ) at 4 and $6 \mathrm{~mm}$ in $135^{\circ}$ meridian and at $6 \mathrm{~mm}$ in $225^{\circ}$ meridian. Conversely, there was a statistically significant flattening ( $\mathrm{p}<0.05$ ) at 2 and $4 \mathrm{~mm}$ in $0^{\circ}$ meridian and at $6 \mathrm{~mm}$ in $90^{\circ}$ and $315^{\circ}$ meridians. In the ICRS group, Table 5 shows the posterior corneal curvature values before and after ScCL wear. These changes are also represented in Fig. 2 There was a statistically significant steeping $(\mathrm{p}<0.05)$ at $2 \mathrm{~mm}$ in $0^{\circ}$ meridian, along the entire $45^{\circ}$ meridian and at $4 \mathrm{~mm}$ in $90^{\circ}$ and $135^{\circ}$ meridians. There was only a statistically significant flattening $(\mathrm{p}<0.05)$ at $8 \mathrm{~mm}$ in $225^{\circ}$ meridian.

The posterior corneal aberrations changes after $8 \mathrm{~h}$ of ScCL wear are shown in Fig. 3. No changes $(p>0.05)$ in posterior corneal aberrations were found in terms of Root Mean Square (RMS), High order Aberrations (HOA) RMS, Low Order Aberrations (LOA) RMS, Z3 
Table 2

Corneal pachymetry and anterior chamber height changes before and after scleral lens wearing. *p value $<0.05$. Student's $t$-test for related samples.

\begin{tabular}{|c|c|c|c|c|}
\hline Test & Visit & Total $(n=26)$ & KC group $(n=13)$ & ICRS group $(n=13)$ \\
\hline Pachymetry apex $(\mu \mathrm{m})$ & Pre - post $8 \mathrm{~h}$ & $-0.285 \pm 14.414$ & $-0.286 \pm 16.776$ & $-0.285 \pm 12.250$ \\
\hline mean $\pm \mathrm{SD}$ & P-value & 0.917 & 0.950 & 0.932 \\
\hline Nasal pachymetry $(\mu \mathrm{m})$ & Pre - post $8 h$ & $7.714 \pm 21.514$ & $6.000 \pm 15.362$ & $9.428 \pm 26.814$ \\
\hline mean $\pm \mathrm{SD}$ & P-value & 0.069 & 0.168 & 0.211 \\
\hline Temporal pachymetry $(\mu \mathrm{m})$ & Pre - post $8 h$ & $-2.571 \pm 18.023$ & $-3.142 \pm 9.355$ & $-2.000 \pm 24.216$ \\
\hline mean $\pm S D$ & P-value & 0.457 & 0.231 & 0.762 \\
\hline Inferior pachymetry $(\mu \mathrm{m})$ & Pre - post $8 h$ & $6.571 \pm 23.281$ & $11.714 \pm 20.782$ & $1.428 \pm 25.236$ \\
\hline mean $\pm S D$ & P-value & 0.147 & $0.049 *$ & 0.836 \\
\hline Superior pachymetry $(\mu \mathrm{m})$ & Pre - post $8 h$ & $13.214 \pm 27.355$ & $8.857 \pm 23.595$ & $17.571 \pm 30.928$ \\
\hline mean $\pm S D$ & P-value & $0.017^{*}$ & 0.184 & $0.047^{*}$ \\
\hline Anterior chamber height (mm) & Pre - post $8 \mathrm{~h}$ & $0.011 \pm 0.069$ & $0.000 \pm 0.026$ & $0.021 \pm 0.095$ \\
\hline mean $\pm S D$ & P-value & 0.420 & 1.000 & 0.414 \\
\hline
\end{tabular}

(oblique astigmatism), Z4 (defocus), Z5 (vertical astigmatism), Z7 (vertical coma), Z8 (horizontal coma) and Z12 (spherical aberration) in any group and pupil diameter, except in $\mathrm{Z} 8$ for $4 \mathrm{~mm}$ in the KC group $(\mathrm{p}<0.05)$.

\section{Discussion}

The development of modern rigid gas permeable (RGP) materials with high oxygen permeability (Dk) have allowed safer wear of contact lenses. However, ScCL wear does reduce the amount of oxygen getting to the cornea due to the lens and the post-lens tear layer thickness $[7,8]$. Hypoxia is a trigger factor for corneal oedema, which could comprise the safety of this optical treatment. Despite the fact that ScCL have become one of the main modes of correction for keratoconus patients, their safety and effect on the anterior segment must be carefully studied. Previous studies have shown the effect of ScCL on ocular surface in keratoconus patients $[9,10,14,15]$. The present study is the first to report on changes in the anterior chamber depth, corneal pachymetry, posterior corneal curvature and aberrations across the cornea after ScCL wear in keratoconus patients with and without ICRS.

All the data was collected from the Pentacam system, which is a reliable and repeatable instrument in keratoconus patients [21]. This study showed a statistically significant thinning of the cornea that affected different regions in each group after $8 \mathrm{~h}$ of ScCL wear. The location of this thinning is the superior quadrant in "all subjects" group and in the ICRS group, while in the KC group, the location was the inferior quadrant (Table 2). The reduction in thickness was $2.03 \%$ in all subjects and the KC group and $2.77 \%$ in the ICRS group. Relative to anterior chamber depth, no statistically significant change was found after $8 \mathrm{~h}$ of scleral lens in any group. Anterior chamber depth and intraocular pressure should be evaluated in future long-term studies to ensure ScCL safety in these parameters.

No consensus on the effect of ScCL wear on corneal thickness has been reached. Some authors found a swelling of the cornea not exceeding 4\%, while others found a corneal thinning [9-13]. In healthy subjects, Vincent et al.[11] did not find differences in corneal thickness after $3 \mathrm{~h}$ of wearing ScCL. However, they reported a thinning $3 \mathrm{~h}$ after scleral lens removal. Vincent et al.[12] and Lafosse et al.[13] showed a corneal thickness increase after $8 \mathrm{~h}$ of wearing ScCL in young and presbyopic subjects. In keratoconus patients, Soeters et al.[9] found a decrease in central corneal thickness 1 week after ScCL removal compared to immediately after ScCL removal, without specifying how many hours they wore the lenses. Additionally, Esen and Toker[10] reported an increase in central corneal thickness after $8 \mathrm{~h}$ of ScCL wear. No

Table 3

Posterior corneal curvature in different points of the cornea before and after scleral lens wearing for the total sample. * $\mathrm{p}$ value $<0.05$. Student's $t$-test for related samples.

\begin{tabular}{|c|c|c|c|c|c|}
\hline \multirow[t]{2}{*}{ Corneal meridian } & \multirow[t]{2}{*}{ Visit } & \multicolumn{4}{|l|}{ Corneal diameter } \\
\hline & & $2 \mathrm{~mm}$ & $4 \mathrm{~mm}$ & $6 \mathrm{~mm}$ & $8 \mathrm{~mm}$ \\
\hline Corneal curvature at $0^{\circ}(\mathrm{mm})$ & Pre & $5.854 \pm 1.054$ & $6.204 \pm 0.826$ & $6.599 \pm 0.595$ & $6.995 \pm 0.421$ \\
\hline mean $(\mathrm{SD})$ & $\begin{array}{l}\text { Post } 8 \mathrm{~h} \\
\text { P-value }\end{array}$ & $\begin{array}{l}5.859 \pm 1.025 \\
0.867\end{array}$ & $\begin{array}{l}6.217 \pm 0.838 \\
0.645\end{array}$ & $\begin{array}{l}6.584 \pm 0.549 \\
0.616\end{array}$ & $\begin{array}{l}6.937 \pm 0.400 \\
0.015^{*}\end{array}$ \\
\hline Corneal curvature at $45^{\circ}(\mathrm{mm})$ & Pre & $6.389 \pm 1.323$ & $6.921 \pm 0.870$ & $7.112 \pm 0.541$ & $7.249 \pm 0.451$ \\
\hline mean $(\mathrm{SD})$ & $\begin{array}{l}\text { Post } 8 \mathrm{~h} \\
\text { P-value }\end{array}$ & $\begin{array}{l}6.286 \pm 1.398 \\
0.103\end{array}$ & $\begin{array}{l}6.806 \pm 0.907 \\
0.014^{*}\end{array}$ & $\begin{array}{l}7.189 \pm 0.432 \\
0.401\end{array}$ & $\begin{array}{l}7.231 \pm 0.376 \\
0.536\end{array}$ \\
\hline Corneal curvature at $90^{\circ}(\mathrm{mm})$ & Pre & $6.072 \pm 1.179$ & $6.754 \pm 0.870$ & $6.886 \pm 0.667$ & $7.121 \pm 0.411$ \\
\hline mean $(\mathrm{SD})$ & $\begin{array}{l}\text { Post } 8 \mathrm{~h} \\
\text { P-value }\end{array}$ & $\begin{array}{l}5.984 \pm 1.286 \\
0.095\end{array}$ & $\begin{array}{l}6.639 \pm 1.039 \\
0.041^{*}\end{array}$ & $\begin{array}{l}6.933 \pm 0.672 \\
0.288\end{array}$ & $\begin{array}{l}7.180 \pm 0.286 \\
0.167\end{array}$ \\
\hline $\begin{array}{l}\text { Corneal curvature at } 135^{\circ}(\mathrm{mm}) \\
\text { mean }(\mathrm{SD})\end{array}$ & $\begin{array}{l}\text { Pre } \\
\text { Post } 8 \mathrm{~h} \\
\text { P-value }\end{array}$ & $\begin{array}{l}5.658 \pm 1.184 \\
5.592 \pm 1.011 \\
0.085\end{array}$ & $\begin{array}{l}6.170 \pm 1.046 \\
6.105 \pm 1.009 \\
0.002^{*}\end{array}$ & $\begin{array}{l}6.626 \pm 0.739 \\
6.567 \pm 0.753 \\
0.027^{*}\end{array}$ & $\begin{array}{l}6.971 \pm 0.364 \\
6.902 \pm 0.220 \\
0.140\end{array}$ \\
\hline $\begin{array}{l}\text { Corneal curvature at } 180^{\circ}(\mathrm{mm}) \\
\text { mean }(\mathrm{SD})\end{array}$ & $\begin{array}{l}\text { Pre } \\
\text { Post } 8 \mathrm{~h} \\
\text { P-value }\end{array}$ & $\begin{array}{l}5.366 \pm 1.078 \\
5.381 \pm 0.992 \\
0.582\end{array}$ & $\begin{array}{l}5.559 \pm 1.008 \\
5.596 \pm 0.975 \\
0.273\end{array}$ & $\begin{array}{l}6.058 \pm 0.774 \\
6.088 \pm 0.760 \\
0.217\end{array}$ & $\begin{array}{l}6.486 \pm 0.452 \\
6.478 \pm 0.455 \\
0.640\end{array}$ \\
\hline $\begin{array}{l}\text { Corneal curvature at } 225^{\circ}(\mathrm{mm}) \\
\text { mean }(\mathrm{SD})\end{array}$ & $\begin{array}{l}\text { Pre } \\
\text { Post } 8 \mathrm{~h} \\
\text { P-value }\end{array}$ & $\begin{array}{l}5.181 \pm 1.181 \\
5.171 \pm 1.168 \\
0.381\end{array}$ & $\begin{array}{l}5.274 \pm 1.160 \\
5.264 \pm 1.083 \\
0.660\end{array}$ & $\begin{array}{l}5.703 \pm 0.809 \\
5.544 \pm 0.850 \\
0.024^{*}\end{array}$ & $\begin{array}{l}5.810 \pm 0.488 \\
5.860 \pm 0.484 \\
0.002 *\end{array}$ \\
\hline $\begin{array}{l}\text { Corneal curvature at } 270^{\circ}(\mathrm{mm}) \\
\text { mean }(\mathrm{SD})\end{array}$ & $\begin{array}{l}\text { Pre } \\
\text { Post } 8 \mathrm{~h} \\
\text { P-value }\end{array}$ & $\begin{array}{l}5.134 \pm 1.423 \\
5.120 \pm 1.397 \\
0.723\end{array}$ & $\begin{array}{l}5.147 \pm 1.272 \\
5.168 \pm 1.323 \\
0.461\end{array}$ & $\begin{array}{l}5.186 \pm 0.681 \\
5.231 \pm 0.732 \\
0.069\end{array}$ & $\begin{array}{l}5.649 \pm 0.494 \\
5.703 \pm 0.468 \\
0.010^{*}\end{array}$ \\
\hline $\begin{array}{l}\text { Corneal curvature at } 315^{\circ}(\mathrm{mm}) \\
\text { mean }(\mathrm{SD})\end{array}$ & $\begin{array}{l}\text { Pre } \\
\text { Post } 8 \mathrm{~h} \\
\text { P-value }\end{array}$ & $\begin{array}{l}5.276 \pm 1.041 \\
5.336 \pm 0.931 \\
0.089\end{array}$ & $\begin{array}{l}5.435 \pm 0.777 \\
5.484 \pm 0.807 \\
0.035^{*}\end{array}$ & $\begin{array}{l}5.455 \pm 0.696 \\
5.672 \pm 0.594 \\
0.014 *\end{array}$ & $\begin{array}{l}6.136 \pm 0.514 \\
5.142 \pm 0.450 \\
0.823\end{array}$ \\
\hline
\end{tabular}


Table 4

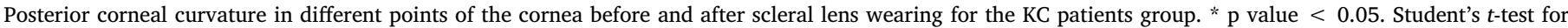
related samples.

\begin{tabular}{|c|c|c|c|c|c|}
\hline \multirow[t]{2}{*}{ Corneal meridian } & \multirow[t]{2}{*}{ Visit } & \multicolumn{4}{|l|}{ Corneal diameter } \\
\hline & & $2 \mathrm{~mm}$ & $4 \mathrm{~mm}$ & $6 \mathrm{~mm}$ & $8 \mathrm{~mm}$ \\
\hline \multirow{3}{*}{$\begin{array}{l}\text { Corneal curvature at } 0^{\circ}(\mathrm{mm}) \\
\text { mean }(\mathrm{SD})\end{array}$} & Pre & $5.791 \pm 1.182$ & $6.154 \pm 1.004$ & $6.616 \pm 0.812$ & $7.157 \pm 0.505$ \\
\hline & Post $8 \mathrm{~h}$ & $5.901 \pm 1.217$ & $6.244 \pm 1.040$ & $6.614 \pm 0.723$ & $7.093 \pm 0.512$ \\
\hline & P-value & $0.001^{*}$ & $0.013^{*}$ & 0.969 & 0.063 \\
\hline \multirow{3}{*}{$\begin{array}{l}\text { Corneal curvature at } 45^{\circ}(\mathrm{mm}) \\
\text { mean }(\mathrm{SD})\end{array}$} & Pre & $6.491 \pm 1.570$ & $6.972 \pm 0.961$ & $7.213 \pm 0.685$ & $7.490 \pm 0.515$ \\
\hline & Post $8 \mathrm{~h}$ & $6.493 \pm 1.794$ & $6.871 \pm 1.094$ & $7.437 \pm 0.380$ & $7.497 \pm 0.324$ \\
\hline & P-value & 0.987 & 0.203 & 0.219 & 0.912 \\
\hline \multirow{3}{*}{$\begin{array}{l}\text { Corneal curvature at } 90^{\circ}(\mathrm{mm}) \\
\text { mean }(\mathrm{SD})\end{array}$} & Pre & $6.226 \pm 1.395$ & $6.786 \pm 0.921$ & $6.870 \pm 0.736$ & $7.342 \pm 0.348$ \\
\hline & Post $8 \mathrm{~h}$ & $6.220 \pm 1.599$ & $6.714 \pm 1.253$ & $6.943 \pm 0.767$ & $7.342 \pm 0.311$ \\
\hline & P-value & 0.922 & 0.461 & $0.004^{*}$ & 1.000 \\
\hline \multirow{3}{*}{$\begin{array}{l}\text { Corneal curvature at } 135^{\circ}(\mathrm{mm}) \\
\text { mean }(\mathrm{SD})\end{array}$} & Pre & $5.549 \pm 1.198$ & $6.027 \pm 1.052$ & $6.519 \pm 0.656$ & $7.080 \pm 0.437$ \\
\hline & Post $8 \mathrm{~h}$ & $5.534 \pm 1.059$ & $5.974 \pm 1.080$ & $6.420 \pm 0.769$ & $6.954 \pm 0.180$ \\
\hline & P-value & 0.725 & $0.019^{*}$ & $0.023^{*}$ & 0.151 \\
\hline \multirow{3}{*}{$\begin{array}{l}\text { Corneal curvature at } 180^{\circ}(\mathrm{mm}) \\
\text { mean }(\mathrm{SD})\end{array}$} & Pre & $5.263 \pm 1.072$ & $5.371 \pm 0.930$ & $5.839 \pm 0.757$ & $6.314 \pm 0.517$ \\
\hline & Post $8 \mathrm{~h}$ & $5.301 \pm 0.999$ & $5.420 \pm 0.885$ & $5.879 \pm 0.735$ & $6.281 \pm 0.534$ \\
\hline & P-value & 0.370 & 0.438 & 0.383 & 0.079 \\
\hline \multirow{3}{*}{$\begin{array}{l}\text { Corneal curvature at } 225^{\circ}(\mathrm{mm}) \\
\text { mean }(\mathrm{SD})\end{array}$} & Pre & $5.091 \pm 1.196$ & $4.916 \pm 0.852$ & $5.506 \pm 0.870$ & $5.639 \pm 0.569$ \\
\hline & Post $8 \mathrm{~h}$ & $5.077 \pm 1.140$ & $4.902 \pm 0.748$ & $5.139 \pm 0.676$ & $5.673 \pm 0.532$ \\
\hline & P-value & 0.755 & 0.705 & $0.002^{*}$ & 0.091 \\
\hline \multirow{3}{*}{$\begin{array}{l}\text { Corneal curvature at } 270^{\circ}(\mathrm{mm}) \\
\text { mean }(\mathrm{SD})\end{array}$} & Pre & $4.781 \pm 1.177$ & $4.651 \pm 0.714$ & $4.979 \pm 0.642$ & $5.633 \pm 0.613$ \\
\hline & Post $8 \mathrm{~h}$ & $4.779 \pm 1.019$ & $4.669 \pm 0.657$ & $5.034 \pm 0.630$ & $5.699 \pm 0.587$ \\
\hline & P-value & 0.962 & 0.608 & 0.060 & 0.070 \\
\hline \multirow{3}{*}{$\begin{array}{l}\text { Corneal curvature at } 315^{\circ}(\mathrm{mm}) \\
\text { mean }(\mathrm{SD})\end{array}$} & Pre & $5.057 \pm 0.935$ & $5.252 \pm 0.796$ & $5.227 \pm 0.667$ & $6.139 \pm 0.687$ \\
\hline & Post $8 \mathrm{~h}$ & $5.153 \pm 0.849$ & $5.306 \pm 0.825$ & $5.669 \pm 0.736$ & $6.164 \pm 0.593$ \\
\hline & P-value & 0.059 & 0.110 & $0.003^{*}$ & 0.596 \\
\hline
\end{tabular}

studies analyzing changes in the anterior chamber depth were found in the scientific literature.

Studies with healthy subjects [11-13] should not be compared or extrapolated to keratoconus patients due to differences in corneal biomechanics and posterior corneal physiology [23]. Two studies looked at central corneal thickness in keratoconus patients $[9,10]$. Their conclusions should be considered cautiously based on our results that show no changes in the apex pachymetry. The reason for sectorial corneal thinning is unclear. These thickness changes could be due to epithelial compression, following the same mechanisms as in orthokeratology $[24,25]$. Another hypothesis could be related to an increase in post-lens tear layer osmolarity during ScCL wear, inducing fluid loss of the stroma resulting in corneal thinning. The only study about ScCL and osmolarity [14] reported a decrease in tear film osmolarity after lens removal, but this would not relate to post-lens tear layer osmolarity during lens wear. On the other hand, the region where thinning varied between the KC and ICRS groups could be related to the differences in biomechanical and posterior physiological properties after ICRS implantation in the inferior region of the stroma [26]. A deeper analysis of potential changes in the epithelium and endothelium would be recommended for future studies to explain these outcomes.

In relation to posterior corneal curvature, we found ScCL wear affected keratoconic corneas with and without ICRS differently. In the KC group, there was a flattening and a steepening in the superior-nasal and temporal regions respectively. On the other hand, in the ICRS group, there was a steepening in the superior region, mainly in the superiornasal meridian, and a flattening that only affected to one peripheral location. These changes in the posterior curvature would not be

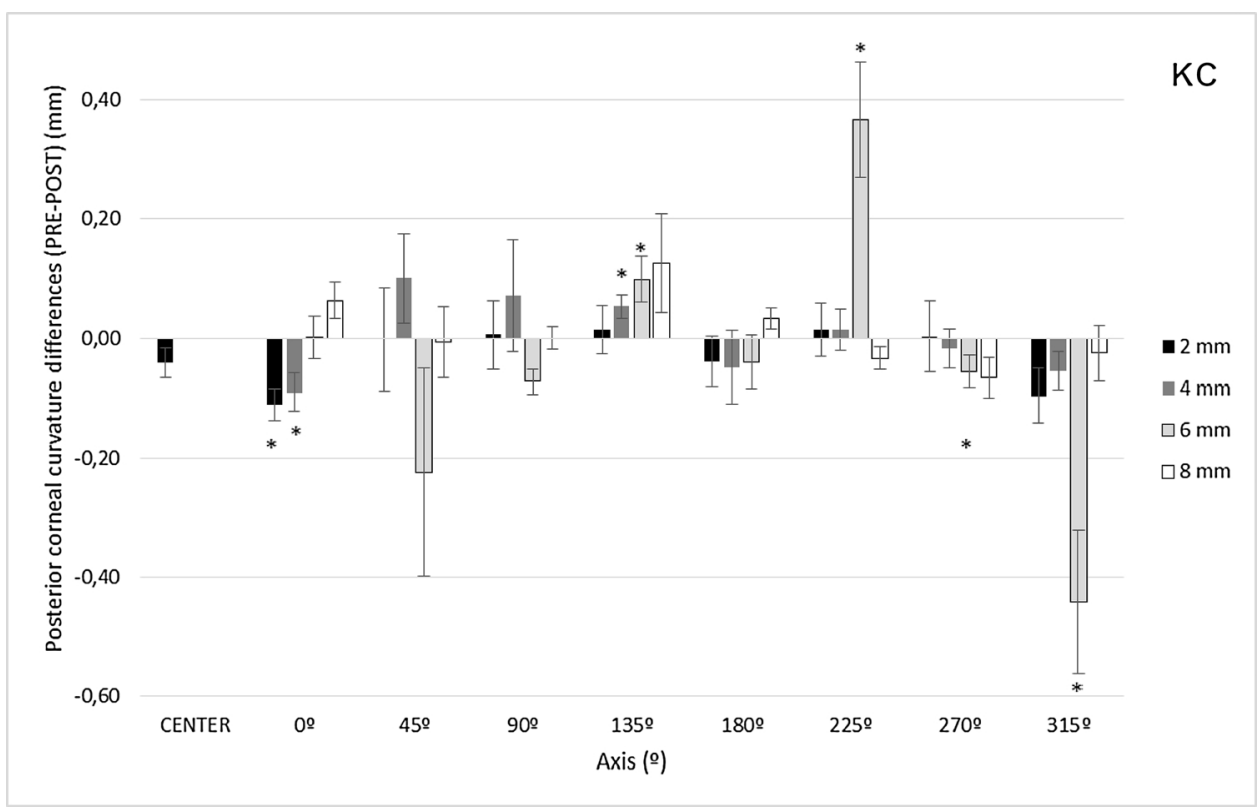

Fig. 1. Posterior corneal curvature difference between before and after scleral contact lens wear in KC group at different positions on the cornea. Positive values mean steepening curvature after ScCL wear and negative values mean flattening curvature after ScCL wear. Error bars represent mean \pm SEM $(n=13)$. $*$ P value $<0.05$, Student's t-test for related samples. 
Table 5

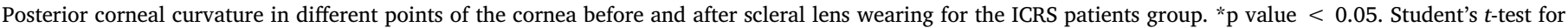
related samples.

\begin{tabular}{|c|c|c|c|c|c|}
\hline \multirow[t]{2}{*}{ Corneal meridian } & \multirow[t]{2}{*}{ Visit } & \multicolumn{4}{|l|}{ Corneal diameter } \\
\hline & & $2 \mathrm{~mm}$ & $4 \mathrm{~mm}$ & $6 \mathrm{~mm}$ & $8 \mathrm{~mm}$ \\
\hline \multirow{3}{*}{$\begin{array}{l}\text { Corneal curvature at } 0^{\circ}(\mathrm{mm}) \\
\text { mean }(\mathrm{SD})\end{array}$} & Pre & $5.917 \pm 0.949$ & $6.254 \pm 0.636$ & $6.581 \pm 0.276$ & $6.857 \pm 0.283$ \\
\hline & Post $8 \mathrm{~h}$ & $5.817 \pm 0.836$ & $6.190 \pm 0.611$ & $6.554 \pm 0.282$ & $6.803 \pm 0.208$ \\
\hline & P-value & $0.014^{*}$ & 0.093 & 0.554 & 0.126 \\
\hline \multirow{3}{*}{$\begin{array}{l}\text { Corneal curvature at } 45^{\circ}(\mathrm{mm}) \\
\text { mean }(\mathrm{SD})\end{array}$} & Pre & $6.286 \pm 1.072$ & $6.871 \pm 0.801$ & $7.011 \pm 0.341$ & $7.042 \pm 0.259$ \\
\hline & Post $8 \mathrm{~h}$ & $6.079 \pm 0.865$ & $6.739 \pm 0.708$ & $6.941 \pm 0.333$ & $7.004 \pm 0.249$ \\
\hline & P-value & $0.023^{*}$ & $0.019^{*}$ & $0.006^{*}$ & $0.025^{*}$ \\
\hline \multirow{3}{*}{$\begin{array}{l}\text { Corneal curvature at } 90^{\circ}(\mathrm{mm}) \\
\text { mean }(\mathrm{SD})\end{array}$} & Pre & $5.919 \pm 0.945$ & $6.723 \pm 0.850$ & $6.905 \pm 0.608$ & $6.900 \pm 0.354$ \\
\hline & Post $8 \mathrm{~h}$ & $5.747 \pm 0.870$ & $6.564 \pm 0.813$ & $6.921 \pm 0.575$ & $7.018 \pm 0.130$ \\
\hline & P-value & 0.053 & $0.010^{*}$ & 0.859 & 0.161 \\
\hline \multirow{3}{*}{$\begin{array}{l}\text { Corneal curvature at } 135^{\circ}(\mathrm{mm}) \\
\text { mean }(\mathrm{SD})\end{array}$} & Pre & $5.767 \pm 1.205$ & $6.313 \pm 1.059$ & $6.734 \pm 0.825$ & $6.861 \pm 0.242$ \\
\hline & Post $8 \mathrm{~h}$ & $5.650 \pm 0.996$ & $6.236 \pm 0.955$ & $6.714 \pm 0.734$ & $6.850 \pm 0.250$ \\
\hline & P-value & 0.073 & $0.035^{*}$ & 0.527 & 0.742 \\
\hline \multirow{3}{*}{$\begin{array}{l}\text { Corneal curvature at } 180^{\circ}(\mathrm{mm}) \\
\text { mean }(\mathrm{SD})\end{array}$} & Pre & $5.469 \pm 1.114$ & $5.746 \pm 1.081$ & $6.277 \pm 0.754$ & $6.659 \pm 0.306$ \\
\hline & Post $8 \mathrm{~h}$ & $5.460 \pm 1.017$ & $5.771 \pm 1.061$ & $6.297 \pm 0.751$ & $6.674 \pm 0.248$ \\
\hline & P-value & 0.809 & 0.397 & 0.311 & 0.624 \\
\hline \multirow{3}{*}{$\begin{array}{l}\text { Corneal curvature at } 225^{\circ}(\mathrm{mm}) \\
\text { mean }(\mathrm{SD})\end{array}$} & Pre & $5.271 \pm 1.204$ & $5.632 \pm 1.340$ & $5.900 \pm 0.720$ & $5.980 \pm 0.329$ \\
\hline & Post $8 \mathrm{~h}$ & $5.237 \pm 1.234$ & $5.626 \pm 1.263$ & $5.949 \pm 0.831$ & $6.046 \pm 0.358$ \\
\hline & P-value & 0.312 & 0.831 & 0.347 & $0.011 *$ \\
\hline \multirow{3}{*}{$\begin{array}{l}\text { Corneal curvature at } 270^{\circ}(\mathrm{mm}) \\
\text { mean }(\mathrm{SD})\end{array}$} & Pre & $5.487 \pm 1.598$ & $5.643 \pm 1.524$ & $5.394 \pm 0.677$ & $5.664 \pm 0.361$ \\
\hline & Post $8 \mathrm{~h}$ & $5.461 \pm 1.663$ & $5.667 \pm 1.634$ & $5.429 \pm 0.796$ & $5.707 \pm 0.332$ \\
\hline & P-value & 0.652 & 0.607 & 0.407 & 0.071 \\
\hline \multirow{3}{*}{$\begin{array}{l}\text { Corneal curvature at } 315^{\circ}(\mathrm{mm}) \\
\text { mean }(\mathrm{SD})\end{array}$} & Pre & $5.496 \pm 1.129$ & $5.618 \pm 0.741$ & $5.683 \pm 0.670$ & $6.133 \pm 0.278$ \\
\hline & Post $8 \mathrm{~h}$ & $5.519 \pm 1.004$ & $5.661 \pm 0.777$ & $5.676 \pm 0.439$ & $6.121 \pm 0.263$ \\
\hline & P-value & 0.644 & 0.194 & 0.928 & 0.730 \\
\hline
\end{tabular}

considered clinically relevant from an optical point of view since the refractive index of the cornea (1.376) and the aqueous humor (1.336) are similar. However, the physiological implications should be considered for future studies.

No studies about the influence of ScCL wear on corneal posterior surface of keratoconus patients were found in the scientific literature. In healthy subjects, only Vincent et al. [12] reported no changes in the central $6 \mathrm{~mm}$ of the posterior corneal surface after $8 \mathrm{~h}$ of scleral lens wear. The changes found in the present study could be related to corneal swelling producing a flattening of the posterior surface [27]. In this case, thinning of the cornea could be producing a contrary effect, a steepening of the posterior surface. In the ICRS group, thinning of the superior quadrant coincides with the steepening of the superior quadrant. However, in the KC group, thinning was found in the inferior quadrant, while steepening occurred in the nasal quadrant. Also, in this group, there was a flattening in the superior-nasal quadrant that does not seem to be related with a corneal swelling in this location.

In relation to posterior corneal aberrations, only the KC group had statistically significant differences in horizontal coma (Z8) for $4 \mathrm{~mm}$ and defocus (Z4) for $8 \mathrm{~mm}$ after ScCL wear. These changes are not clinically relevant because there were not changes in HOA RMS or LOA RMS. The variations in Z8 are associated with an elevation of the posterior corneal surface in the horizontal meridian, coinciding with the location of the posterior corneal curvature changes. No studies analyzing the posterior corneal aberrations after scleral lens wear were found in the scientific literature.

This study presents some limitations that must be considered. Tear exchange and tear clearance under the lens in the different quadrant, to

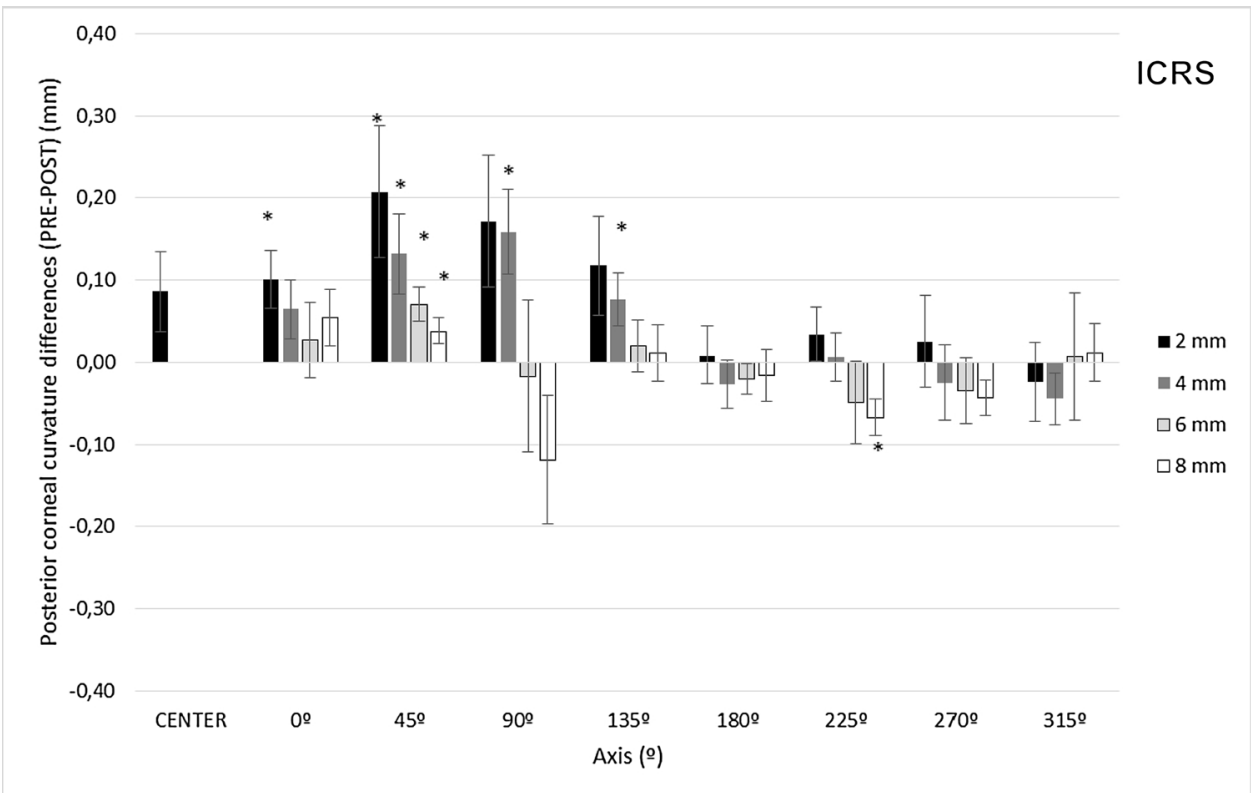

Fig. 2. Posterior corneal curvature difference between before and after scleral contact lens wear in ICRS patients at different positions on the cornea. Positive values mean steepening curvature after ScCL wear and negative values mean flattening curvature after ScCL wear. Error bars represent mean \pm SEM $(n=13)$. $*$ P value $<0.05$, Student's t-test for related samples. 


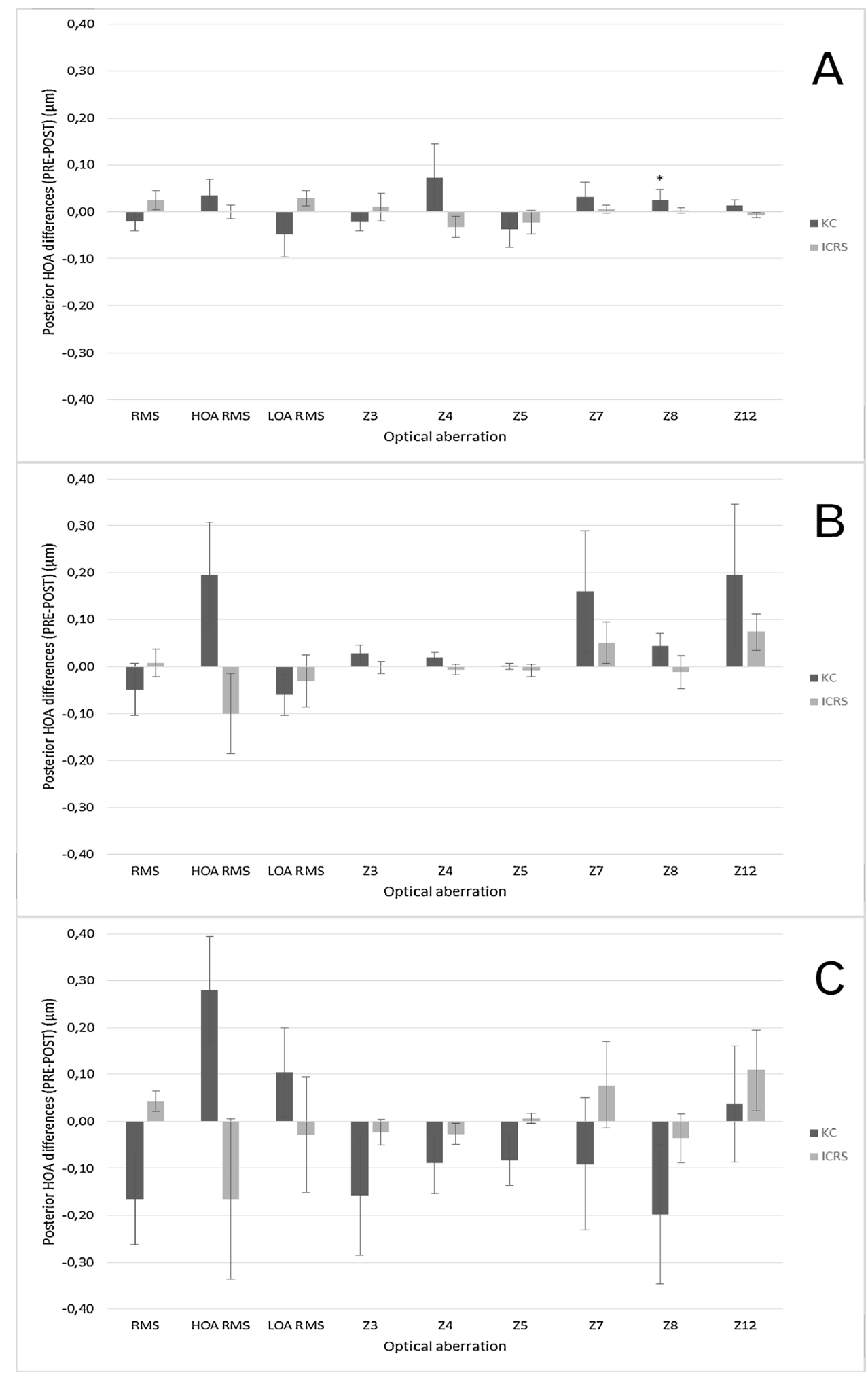

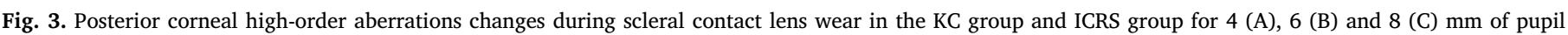

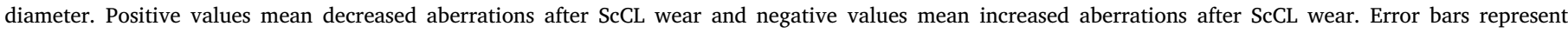
mean \pm SEM $(n=13) .{ }^{*} \mathrm{p}<0.05$, Wilcoxon test.

establish the theoretical $\mathrm{Dk} / \mathrm{T}$ value of the lens system, have not been evaluated. These parameters could be explain some relationship between corneal thickness and posterior curvature and hypoxia and oedema. The parameters analyzed in the present study do not help explain the mechanism of the changes in thickness and pachymetry. Development of a new method to analyze the post lens tear layer osmolarity and the in-vivo analysis of the endothelium and Descemet's membrane may help clarify the previous hypothesis proposed in this section about why these changes occur. In order to confirm the safety and clinical implications of scleral lens treatment for keratoconus, new long-term studies evaluating other study variables as previously mentioned should be addressed. Moreover, in this research, the ICRS were 
located in the inferior corneal but the methodology used was not sufficient accuracy to correlate the stromal rings position and the curvature and pachymetry changes in this area without bias. Specific studies about the correlation between these parameters could be interesting.

In conclusion, short-term ScCL wear showed a thinning of the cornea and changes in the posterior corneal curvature that appears to affect to different regions in keratoconus with and without ICRS. The thinning of the cornea affects the inferior and superior regions in the KC and ICRS groups respectively. In addition, it produced a flattening and a steepening of the superior-nasal curvature in the KC and ICRS groups respectively. ScCL wear also induced a steepening of the nasal curvature in the KC group. However, additional long-term follow-up studies are necessary to understand the mechanisms of these changes and their clinical relevance.

\section{Disclosure}

The authors report no conflicts of interest and have no proprietary interest in any of the materials mentioned in this article

\section{References}

[1] I. Ortenberg, S. Behrman, W. Geraisy, I.S. Barequet, Wearing time as a measure of success of scleral lenses for patients with irregular astigmatism, Eye Contact Lens 39 (2013) 381-384.

[2] M.M. Schornack, J. Pyle, S.V. Patel, Scleral lenses in the management of ocular surface disease, Ophthalmology 121 (2014) 1398-1405.

[3] J. Sonsino, D.S. Mathe, Central vault in dry eye patients successfully wearing scleral lens, Optom Vis Sci 90 (2013) e248-e251 discussion 1030.

[4] E. van der Worp, D. Bornman, D.L. Ferreira, M. Faria-Ribeiro, N. Garcia-Porta, J.M. Gonzalez-Meijome, Modern scleral contact lenses: a review, Contact Lens Anterior Eye 37 (2014) 240-250.

[5] M. Romero-Jimenez, P. Flores-Rodriguez, Utility of a semi-scleral contact lens design in the management of the irregular cornea, Contact Lens Anterior Eye 36 (2013) 146-150.

[6] A.J. Foss, T.C. Trodd, J.K. Dart, Current indications for scleral contact lenses, CLAO J 20 (1994) 115-118.

[7] V. Compan, C. Oliveira, M. Aguilella-Arzo, S. Molla, S.C. Peixoto-de-Matos, J.M. Gonzalez-Meijome, Oxygen diffusion and edema with modern scleral rigid gas permeable contact lenses, Invest Ophthalmol Vis Sci 55 (2014) 6421-6429.

[8] C.J. Giasson, J. Morency, M. Melillo, L. Michaud, Oxygen tension beneath scleral lenses of different clearances, Optom Vis Sci 94 (2017) 466-475.
[9] N. Soeters, E.S. Visser, S.M. Imhof, N.G. Tahzib, Scleral lens influence on corneal curvature and pachymetry in keratoconus patients, Cont Lens Anterior Eye 38 (2015) 294-297.

[10] F. Esen, E. Toker, Influence of apical clearance on mini-scleral Lens settling, clinical performance, and corneal thickness changes, Eye Contact Lens 43 (2017) 230-325.

[11] S.J. Vincent, D. Alonso-Caneiro, M.J. Collins, Corneal changes following short-term miniscleral contact lens wear, Contact Lens Anterior Eye 37 (2014) 461-468.

[12] S.J. Vincent, D. Alonso-Caneiro, M.J. Collins, A. Beanland, L. Lam, C.C. Lim, et al., Hypoxic corneal changes following eight hours of scleral contact Lens wear, Optom Vis Sci 93 (2016) 293-299.

[13] E. Lafosse, D.M. Romin, J.J. Esteve-Taboada, J.S. Wolffsohn, C. Talens-Estarelles, S. Garcia-Lazaro, Comparison of the influence of corneo-scleral and scleral lenses on ocular surface and tear film metrics in a presbyopic population, Cont Lens Anterior Eye. (2017).

[14] G. Carracedo, M.S. Blanco, A. Martin-Gil, W. Zicheng, J.C. Alvarez, J. Pintor, Shortterm effect of scleral Lens on the dry eye biomarkers in keratoconus, Optom Vis Sci 93 (2016) 150-157.

[15] G. Carracedo, Z. Wang, M. Serramito-Blanco, A. Martin-Gil, J. Carballo-Alvarez, J. Pintor, Ocular surface temperature during scleral Lens wearing in patients with keratoconus, Eye Contact Lens 43 (2017) 346-351.

[16] S.J. Vincent, D. Alonso-Caneiro, M.J. Collins, Miniscleral lens wear influences corneal curvature and optics, Ophth Physiol Opt 36 (2016) 100-111.

[17] D.A. Luce, Determining in vivo biomechanical properties of the cornea with an ocular response analyzer, J Cataract Refract Surg 31 (2005) 156-162.

[18] R.F. Hess, L.F. Garner, The effect of corneal edema on visual function, Invest Ophthalmol Vis Sci 16 (1977) 5-13.

[19] G. Carracedo, M. Serramito-Blanco, A. Martin-Gil, Z. Wang, C. Rodriguez-Pomar, J. Pintor, Post-lens tear turbidity and visual quality after scleral lens wear, Clin Exp Opt (2017).

[20] J.R. Williams, The declaration of Helsinki and public health, Bull World Health Organ 86 (2008) 650-652.

[21] B. de Luis Eguileor, J. Escudero Argaluza, J.I. Pijoan Zubizarreta, A. Santamaria Carro, J. Etxebarria Ecenarro, Evaluation of the reliability and repeatability of scheimpflug system measurement in keratoconus, Cornea (2017).

[23] A. Martinez-Abad, D.P. Pinero, New perspectives on the detection and progression of keratoconus, J Cataract Refract Surg 43 (2017) 1213-1227.

[24] A. Nieto-Bona, A. Gonzalez-Mesa, M.P. Nieto-Bona, C. Villa-Collar, A. LorenteVelazquez, Short-term effects of overnight orthokeratology on corneal cell morphology and corneal thickness, Cornea 30 (2011) 646-654.

[25] A. Nieto-Bona, A. Gonzalez-Mesa, M.P. Nieto-Bona, C. Villa-Collar, A. LorenteVelazquez, Long-term changes in corneal morphology induced by overnight orthokeratology, Curr Eye Res 36 (2011) 895-904.

[26] D.P. Pinero, J.L. Alio, R.I. Barraquer, R. Michael, Corneal biomechanical changes after intracorneal ring segment implantation in keratoconus, Cornea 31 (2012) 491-499.

[27] D.W. Del Monte, T. Kim, Anatomy and physiology of the cornea, J Cataract Refract Surg 37 (2011) 588-598. 